\title{
CONTO DOIS
}

Del Candeias (Daniel Levy Candeias) ${ }^{1}$

Graças a... Graças a minha tia, dinheiro não me falta e me encontro numa situação em que, se, por exemplo, eu quiser tomar um café da manhã na Austrália, posso ir imediatamente sem que isso atrapalhe de forma alguma o meu cotidiano e as minhas finanças. Minha tia não era fácil e montou um verdadeiro império que deixou nas minhas mãos.

Essa tia tinha quatro irmãos. Comigo, eram doze sobrinhos. Todos eles tinham realizado o mesmo projeto familiar: ter três filhos, para aumentar o número de descendentes nossos mundo. Ela, porém, até nisso mostrava que preferia trilhar seu próprio caminho, pois abdicou de ser mãe.

Desde quando eu era muito pequenininho, nos dávamos muito bem. Nem me lembro de quais foram os primeiro sinais de nossa afinidade. Para ser franco, não me lembro de período nenhum da minha infância que seja anterior às nossas brincadeiras, conversas e passeios. Também não sei por que estreitamos uma relação tão forte. Qualquer hipótese que me vem à cabeça não parece explicar direito esse fato. Talvez tenha sido aquele tipo de amizade que começa do nada, por pura empatia. Só que, dessa vez, um dos amigos ainda nem sabia falar.

Bem... Isso não importa. O que importa é que sempre fôramos grandes amigos. Desde muito criança eu frequentava a casa dela, ela aparecia em algumas reuniões do colégio e torcia fervorosamente nos campeonatos de futebol dos quais participava. Como não tinha filhos, talvez isso fosse um jeito de despertar um pouco seu instinto materno; de fato, para mim, ela sempre foi uma segunda mãe e meus pais não tinham problema algum com isso. Muito pelo contrário, como todos os outros integrantes da família, adoravam-na. Por isso era comum aproveitarem para nos acompanhar nos nossos passeios, levando, inclusive, meus dois irmãos mais novos. E ficavam muito satisfeitos nas vezes em que a tia me buscava em algum lugar ou me ajudava a estudar, quando não tinham tempo.

\footnotetext{
${ }^{1}$ Doutorando em Teoria Literária e Literatura Comparada (FFLCH-USP)
} 
Sendo assim, ela esteve do meu lado durante todo meu amadurecimento, desde a infância, passando pela adolescência, até meus trinta anos. Foi uma grande amiga, a quem devo muitos ensinamentos e muitos anos de companheirismo. Ninguém conseguiu substituir essa figura na minha vida. Nem mesmo a minha esposa, que é uma excelente companheira. Pelo menos uma vez por semana, me dou conta, como se fosse novidade, de que não podemos mais ter nossas conversas quase diárias pelo telefone. Ela se foi e deixou comigo uma herança e um buraco.

Se fosse possível, eu faria um acordo inverso com o Diabo: dava toda minha fortuna para receber em troca a alma da tia.

Como dizia, ela presenciou meu amadurecimento etapa por etapa. O mesmo posso dizer com relação a mim no que concerne a seu sucesso como empresária. Até mais ou menos meus dez anos, ela não era mais rica que os outros familiares. É certo que tinha um restaurante, onde não faltavam fregueses, mas isso só a tornava uma mulher bem estabelecida, jamais uma milionária.

Com o tempo, já não era um, mas dois restaurantes. Depois viraram quatro. Daí ela começou com a padaria, que também se multiplicou. Então, não sei como, ela entrou no ramo de postos de gasolina. E as coisas não pararam por aí... Mas não vem ao caso ficar aqui revelando quantos bens a minha tia possuía e deixou para mim, até mesmo por uma questão de etiqueta. O necessário é saber que aquela mulher não errava nunca a mão e era insaciável. Quando resolvia tocar um negócio para frente, ninguém a segurava. E, logo depois, quando ele despontava, perdia a graça para ela, que dirigia seus esforços a outro empreendimento.

Apesar de nunca ter sido muito afeito a esse tipo de coisa e de não ter jeito nenhum para lidar com dinheiro, eu admirava muito o desempenho daquela mulher. Perguntava sobre cada detalhe, conversávamos horas acerca de estratégias e futuros projetos. Vez por outra, ela até me explicava mecanismos financeiros e conceitos econômicos. Eu não entendia patavinas e nem me interessava de verdade pelo assunto, mas gostava muito de vê-la envolvida nas suas atividades. Assim ela deve ter feito comigo, quando me ouvia falar sobre minha paixões de criança, como superheróis ou dinossauros. Bem... De qualquer jeito, quando se tem diante de si um bom café e um amigo de verdade, o assunto é o que menos importa. 
Mas voltando... Éramos de fato muito próximos e por isso ela fez um testamento, me deixando tudo o que tinha. Se você não acreditou; para mim foi muito mais incrível. De um dia para o outro, eu, que havia chegado somente a um lugar médio na minha área, tornei-me um milionário. Foi extasiante e ao mesmo tempo assustador. Imaginem a minha cara quando recebi a notícia... E o medo da reação dos parentes? Como a tia não havia deixado mais nada para ninguém?

Por sorte a família respondeu muito bem à situação. Ninguém contestou o testamento, ninguém me acusou de nada e, mais espantoso ainda, ninguém me pediu um centavo sequer. E olha que tinha gente endividada no bolo.

Pedindo ou não pedindo, é claro que eu não ficaria com tudo e arranjei alguns administradores que cuidam do negócio e distribuem uma parte considerável do lucro aos meus tios e meus pais.

Até agora mencionei apenas o trabalho da tia e não disse nada a respeito do que ela fazia nas horas de lazer, a não ser o tempo que passava comigo.

Você já deve imaginar como ela era inteligente. E era mesmo. Sabia tudo de negócios, dobrava qualquer um nas reuniões e, além disso, conhecia muito da vida. De pouquinho em pouquinho, oferecia-me seus conhecimentos, como se os tirasse de um saco de doces.

Porém ela tinha um sério problema que até hoje não consigo entender. Sabe aquelas igrejas que têm programa na televisão com bispo fazendo milagre? Que cobram dinheiro dos fiéis na cara dura? Pois então... Ela não só frequentava uma delas, como, rigorosamente todo mês, deixava altas somas nas mãos daqueles picaretas. Eu ficava admirado. Como uma mulher tão inteligente e, mais ainda, versada em negócios, caía numa pilantragem daquelas? Com o perdão da sinceridade, mas só gente muito modesta, que não teve oportunidade de estudar e não recebeu uma boa educação, é suscetível a esse tipo de influência. Digo só, mas devo contar também a tia, que, umas duas vezes por semana, estava lá na igreja, pedindo conselhos ao bispo, doando dinheiro àquela súcia de pilantras.

O pior é que esse assunto não se limitava ao espaço da igreja. Não era incomum ela pregar para quem estava a sua volta. Sua casa e seu escritório eram repletos santinhos e bíblias. E o que mais me envergonhava e surpreendia é que ela 
forrava seus carros de adesivos com as frases religiosas mais kitsches do mundo. Isso era o único ponto chato nela; mas era bem chato.

Lembro ainda hoje de um dia em que ela havia me buscado no colégio e estávamos assistindo TV, enquanto almoçávamos. Eu tinha acabado de começar o terceiro colegial. Comíamos tranquilamente aquelas maravilhas que só sua cozinheira sabia fazer. A apresentadora do jornal dava as mesmas notícias de sempre. Sob a suave luz do sol, as árvores resplandeciam belamente em seu jardim. Até que uma inocente matéria veio desfazer a nossa paz.

Tratavam de um artista plástico que havia causado muita polêmica no nosso país. Todos os seus trabalhos centravam-se na figura de Jesus. Sempre com viés blasfematório. Para se ter uma ideia, uma das obras das quais nunca me esqueci desde aquele dia era uma escultura de mármore que representava um falo crucificado.

Quando viu aquilo, minha tia quase teve uma síncope. Como podia deixarem alguém fazer aquilo com a imagem de Cristo? Aonde o mundo iria parar? Mas aquele homem iria arder no fogo do inferno! E por aí vai...

Confesso que não fiquei tão insatisfeito. Primeiro, porque nunca gostei muito das religiões ligadas a Cristo. Tinha estudado em colégio de padre por algum tempo e descobri até que ponto essa raça é suscetível ao uso da coerção e da arbitrariedade. Depois que passei um ano num internato, fiquei assombrado com a perversão, mesmo e sobretudo sexual, dessa gente. Segundo, porque a imagem era divertida, pois simbolizava muito bem a fase que eu estava vivendo. Adolescente, virgem, sondado pelos pais, eu não era nada mais, nada menos do que aquilo: um falo crucificado. Aliás, com isso, lembrava também da maldita freira do internato que se insinuava e me provocava o tempo todo para desaparecer no momento em que podia rolar alguma coisa... Terceiro, porque não suportava a religiosidade tola da minha tia e, nesse sentido, a escultura funcionava como um protesto.

Nunca, porém, maldisse tanto um dia quanto aquele. A mulher encafifou de vez com o artista não só durante a tarde toda, como durante toda vida. Tudo era motivo para colocá-lo no meio. Se os EUA declaravam guerra ao Iraque, isso só podia ser efeito de uma sociedade em que obras como o falo crucificado eram aceitas. Se crianças ateavam fogo num mendigo, a razão estava na educação carente de religião, 
deixando-as expostas a uma cultura na qual os artistas maculavam as imagens divinas. E o tema, vez por outra, surgia do nada: a tia iniciava seu ataque como um velho cego que balança a bengala no ar.

De todo modo, sempre respeitamos sua opção religiosa. Eu, mesmo quando muito novinho, nunca me atrevi a fazer uma brincadeirinha, nem tentei abrir seus olhos para as malandragens óbvias de sua igreja. No seu velório, chamamos inclusive um bispo de lá, por puro respeito a suas vontades e a sua memória.

Voltando...

Depois que resolvi a administração do dinheiro e dos negócios, minha vida ficou bastante tranquila. De vez em quando precisava solucionar um problema burocrático, mas, de resto, sem esnobismo, havia poucas obrigações que não pudessem ser cumpridas por uma ou mais pessoas bem pagas. O que, evidentemente, tornou meu dia a dia tedioso. Também fiquei sem norte, porque de repente não havia mais como subir na vida e eu não tinha interesse em me destacar em nenhuma área profissional.

Foi aí que entrou um grande hobby que eu cultivo até hoje: colecionar.

Tudo começou quando fui jantar na casa de um parceiro, um rapaz muito gentil que gostava muito de receber as pessoas. Mal cheguei, ele abriu um belo Bordeaux e foi me mostrar suas coleções. Primeiro, apresentou seus móveis, finíssimos, e depois, o que mais me apaixonou, suas obras de arte. Portinari, Modigliani, Paulo Pasta, Lygia Clark, Goeldi, Oiticica, Flávio de Carvalho, Grassman, Mira Schendel, Lasar Segall, Farnese...

Numa situação qualquer eu já teria ficado maravilhado, inspirado pelo vinho então... Diante daquilo tudo tive a sensação de nunca ter visto algo tão maravilhoso na minha vida. Pensando agora, acho que não tinha me interessado por artes plásticas até aquele momento, porque nunca havia sequer entrado em um museu. E toda a obra é irredutível a uma reprodução fotográfica.

Foi uma noite excelente e inesquecível. Quando meu colega conduziu-me pelos salões e corredores, discorrendo sobre a história de cada peça e de sua aquisição, percebi que aquilo era uma forma de trazer um pouco de sensibilidade e 
humanidade para nossas mansões esfriadas pelo dinheiro. Sabendo de suas participações em curadoria, além dos empréstimos de obras para exposições, me dei conta de que colecionar era também um modo de participar do meio artístico, mesmo sem saber manejar um pincel.

Na mesma semana adquiri um quadro, que não é muito bom, mas continua na minha coleção por motivos sentimentais. Daí por diante, fui me especializando; até hoje estudo estética, história da arte e filosofia. Mas minha maior especialidade, provavelmente por influência da tia, tem a ver com negócios. Acabei ficando conhecido no mercado por conseguir os melhores preços e obras que não são nada fáceis de encontrar. E fiquei conhecido principalmente por "descobrir" talentos. Em outras palavras, por investir em artistas que despontam logo depois das aquisições.

Não que eu estivesse ou esteja interessado em lucro. De maneira alguma. É que quem mexe com artes plásticas sabe: quanto mais o gosto refina, mais o dinheiro rareia. E, só aprendendo a lidar com o mercado, podemos montar uma coleção considerável e de bons trabalhos.

Nesse meio tempo, é claro que cruzei novamente com o artista odiado pela minha tia. Não só cruzei com ele, como o conheci pessoalmente. Chegamos a ficar meio amigos e, uma ou duas vezes, tomamos um café juntos. E a obra do falo? Revi-a mais de uma vez. Ao vivo e a cores, ela era ainda mais impressionante.

O problema é que passei a admirar profundamente o trabalho desse artista. Não direi que foi por ironia do destino, porque se trata de um reconhecimento quase unânime. Quase todos que fazem parte do meio colocam-no entre os maiores do país. E quem não tem tanto apreço por ele jamais se atreveria a criticá-lo. Do contrário, cairia no ridículo.

A obra do falo, por exemplo, que parece ser uma simples provocação, é na verdade uma grande síntese. Ali estão discutidos sexualidade e dominação como um dos motores do desenvolvimento social brasileiro; uma crítica à filosofia de Foucault; a necessidade e ao mesmo tempo anacronismo das teorias do sujeito e a crise das formas fixas e inovadoras na Pós-modernidade. Além disso, a técnica empregada é fenomenal. As referências vão desde Aleijadinho a Nuno Ramos, combinando elementos do concretismo mais sóbrio com um virtuosismo rococó. 
Trata-se de um artista extraordinário com uma obra ímpar. E, dele, eu não possuía uma obra sequer...

Como poderia colocar um quadro dele na casa que foi da minha tia? Justo na casa daquela que fora a minha maior companheira, a mulher que deixou a minha vida resolvida e que tanto o odiava.

Sei que esse respeito pode parecer zeloso demais. Eu também acho que é. Mas é difícil dominar nossos fantasmas. Na verdade, depois de tomar conhecimento de que as referências a Cristo eram um meio de criar, na verdade, uma paródia de estética do blasfematório, ou seja, que o ponto central das obras nunca tinha a ver com religião, cheguei até a pensar que, se a tia pudesse entender esse recurso, não levaria a mal minha admiração. Ela era uma mulher muito inteligente, mas sua inteligência estava toda voltada para coisas práticas. No entanto, sempre que eu pensava em comprar alguma obra desse artista, era assolado por um forte sentimento de culpa, associado a um medo inexplicável. E assim adiei eternamente essa possibilidade.

Eis que um dia fui ao MAM com um amigo. Tínhamos combinado de ver uma exposição, reduzida, mas interessante que ficaria ali por pouco tempo.

Como era de se esperar, aproveitamos o ensejo para almoçar e colocar a conversa em dia. Assim que começamos, avistei, através do vidro do restaurante, um homem andando muito rapidamente. Ele parecia bastante inquieto: olhava para os lados sem parar e não sabia se levava as mãos ao rosto ou se as deixava nos bolsos, descansando. À medida que foi se aproximando, percebi quem era: o artista da obra do falo. E qual não foi minha surpresa, quando ele, ao me avistar, aproximou-se com uma expressão de satisfação e, do outro lado do vidro, gesticulou indicando que entraria para falar comigo.

Entrou, disse para mim "era você mesmo que eu estava procurando" e cumprimentou-nos. Perguntou se poderia falar comigo depois do almoço (é claro que respondi "sim"), desculpou-se pela interrupção, pediu que por favor não nos apressássemos e foi ver a exposição enquanto acabávamos.

É claro que não nos apressamos, mas também é claro que não nos alongamos. E, em uns vinte minutos, meu amigo cedia seu lugar para o artista. 
Ele aparentava estar aflito e desculpou-se novamente pela maneira com a qual me abordou. Disse que seria breve e foi mesmo. Por um motivo pessoal, que ele preferia não expor, ficara repentinamente num grande aperto financeiro, ou seja, precisava rapidamente de dinheiro. Então me revelou que admirava muito meu gosto e minha coleção. Sabia que eu era uma pessoa mais do que discreta. Sabia também que eu não tinha nenhuma obra dele. A proposta era eu comprar uma série de quadros que ele acabara de compor por um preço bem camarada. De quebra, ele ofereceu-me como presente e prova de sua admiração, se eu adquirisse a série, o famigerado falo crucificado, segundo ele, seu trabalho favorito.

Dali fomos direto para o seu ateliê.

A série era muito impressionante! A última vez que eu tinha ficado tão embasbacado com uma obra de arte tinha sido na exposição do Anish Kapoor no Centro Cultural Banco do Brasil. Não escondi meu encantamento, mas, seguindo a boa educação, não fui pressionado: combinamos que daria minha resposta no dia seguinte.

Num dia só, a possibilidade de fazer o maior negócio da minha vida e ter na minha coleção as melhores obras do meu artista favorito. Foi aí que a imagem da tia surgiu com toda força. E trouxe consigo, mais intensos do que nunca, a culpa e o medo. Fiquei com ódio dela, da Igreja e de mim mesmo. Não sabia o que fazer e, quanto mais eu me assegurava de que aquele era um dilema idiota e de que não havia problema nenhum em adquirir os quadros, mais os pensamentos se obscureciam e os sentimentos se embaralhavam.

Ainda bem que eu tinha marcado uma ceveja com uns amigos. Se eu ficasse em casa, iria enlouquecer.

Como não estava com a cabeça boa, desmarquei a reunião que tinha no museu que presido e fui para o consultório de um dos meus amigos. Ele é psicólogo e atende numa pequena vila em Pinheiros, onde deixo meu carro, sempre quando saímos para beber. Logo que cheguei, telefonamos para nosso outro amigo, que estava num empório ali perto. Sugerimos que nós jantássemos lá. Ele não achou a ideia boa, pois o lugar estava "prosaico". Não entendemos o que ele queria dizer com "prosaico", mas concordamos em ir para outro lugar. 
Fomos a um pub que tinha sido inaugurado recentemente. Um local bonito, bastante agradável, com uma comida muito bem feita e umas cervejas diferentes.

Sentamos e ficamos jogando conversa fora.

Para falar a verdade, não sou uma pessoa muito extrovertida. Por isso, normalmente, participo desses encontros mais ouvindo do que falando. O que não me desagrada nenhum pouco. É meu jeito. Mas tenho certo receio de, assim, não ser tão boa companhia. Naquele dia, em que eu estava com a cabeça atormentada, meu silêncio deve ter sido ainda maior e mais profundo. Durante algum tempo temi somar ainda mais essa preocupação às outras.

Por sorte um dos meus amigos achou logo um assunto. Nunca vi alguém para arranjar tanta história em bar. Um dia conquista uma desconhecida; no outro, está com a amiga dela sem causar desentendimento nenhum; depois, no outro, faz amizade com o bar inteiro; no outro ainda, encontra alguém para discutir algum tema bem esdrúxulo de filosofia. Houve uma vez em que, depois de o procurarmos muito, o encontramos na cozinha, à frente do fogão, com avental e chapéu de cozinheiro. E teve até uma ocasião em que ele, sem saber, fez amizade com uma mulher importante de uma das editoras para as quais trabalha e passou a receber mais.

Naquela noite, o assunto foi bastante simples: apenas duas mulheres que estavam sentadas numa mesa perto de nós. Acontece que esse amigo não é exatamente discreto, quando se sente atraído por uma mulher. Se estiver bêbado, então, é muito engraçado... E ele já estava bem altinho. Olhava o tempo todo para elas, expunha-nos declarações de amor, virava a cerveja em poucos minutos de tão ansioso.

No meio de um de seus arroubos, meu outro amigo comentou que não achava graça nas duas. Ele falou aquilo, certamente, para irritar nosso colega apaixonado, que, quando bêbado, se indispõe facilmente diante de uma contrariedade. E ele fica ótimo indisposto.

Naturalmente esse comentário iniciou uma longuíssima e exaltada discussão. Aí sim a noite foi ficando divertida. Animado por mais umas cervejas e um gim, esqueci o suficiente a história da compra e entrei na brincadeira, incentivando nosso colega atingido pela flecha de Cupido a ir falar com as moças, perguntando ao outro 
por que ele não as tinha achado interessantes. Com elas, aliás, havia dois rapazes que não pareciam ser dos mais refinados. Viraram também objeto de piada e assim tivemos assuntos nobres e profundos para toda a noite.

Mesmo quando fomos obrigados a mudar de bar, porque o primeiro fechara, continuaram a alimentar nossa conversa. Eu, por minha vez, acabei ficando meio calado, mas nenhum de meus amigos pareceu se importar. Esses são os verdadeiros amigos: os que te conhecem e não esperam nada além do conhecido.

Quando o segundo bar anunciou a saideira, a questão da compra voltou a me assombrar. Com ela, voltaram minha tia, a Igreja, meus medos, minha autocrítica etc., mas, dessa vez, com menos força, porque eu estava entorpecido pelo álcool.

Fomos ao consultório, despedi-me de meus amigos, que me ajudaram tanto naquela noite sem saber, e fui embora. No carro estabeleci para mim mesmo que só decidiria sobre a série de quadros, no dia seguinte, quando acordasse. Peguei o caminho de sempre, lentamente, tentando curtir a noite e a música que tocava. Como não podia deixar de ser, passei por uma Igreja, diante da qual minha tia fazia indefectivelmente o sinal da cruz.

Foi, então, que surgiu um violento sentimento de ódio.

Não sei exatamente por que comecei a dar voltas naquele quarteirão. Eu circulava, circulava e circulava, fitando a igreja e alimentando minha ira, como se alguma coisa fosse acontecer. Subitamente parei meu carro, saí e encarei a cruz que se ostentava no alto, feito alguém que desafia um inimigo. Procurei um milagre no chão, mas encontrei apenas uma pedra, que peguei e arremessei com toda precisão contra um vitral que representava Maria Madalena. Lembro até hoje da chuva de estilhaços. Uma verdadeira obra de arte. 